\title{
Effect of Plant Extracts on the Postharvest Performances of Vegetables
}

Authors: Rubaiya Pervin ${ }^{1}$, Shamim Ahmed Kamal Uddin Khan ${ }^{2 *}$, Sabiha Sultana ${ }^{2}$, Mehnaj Tabassum ${ }^{1}$ and Jeba Afroza Jui ${ }^{1}$

${ }^{1}$ Department of Food and Nutrition, Khulna City Corporation Women's College, affiliated to Khulna University, Khulna

${ }^{2}$ Agrotechnology Discipline, Khulna University, Khulna-9208, Bangladesh

*Corresponding author: Khan, S.A.K.U.; E-mail: samkuk_bd@yahoo.com

\section{A B S T R A C T}

Plant extracts are recognized as safe and low-cost materials for postharvest treatments to increase the shelf life of horticultural commodities. However, in Bangladesh plant extracts are rarely used and very little research outcomes have been reported in Bangladesh context. Hence the current study was conducted to evaluate the effectiveness of

Received:

26 November, 2018

Accepted:

06 January, 2019

Online:

31 March, 2019

Key words:

Botanical extract, Bitter gourd, Pointed gourd, Brinjal, Postharvest properties and shelf life combined botanical extracts in maintaining postharvest physico-chemical properties and extending shelf life of some summer vegetable (Bitter gourd, Brinjal and Pointed gourd) of Bangladesh. Freshly harvested vegetables were left untreated (control- $\mathrm{T}_{1}$ ) or treated with combination of aloe vera and thankuni extracts $\left(\mathrm{T}_{2}\right)$; onion, garlic and ginger extracts $\left(\mathrm{T}_{3}\right)$; aloe vera, thankuni, onion, garlic and ginger extracts $\left(\mathrm{T}_{4}\right)$. Then they were kept for two weeks in uncovered paper carton in ambient conditions to observe their postharvest performances in respect of microbial infection (\%), total soluble solids (\% Brix), $\mathrm{pH}$ (magnitude), ascorbic acid content (mg/100 g), weight loss (\%), shelf life (days), firmness (score) and color (score). In comparison to the control $\left(\mathrm{T}_{1}\right)$, the postharvest properties were well maintained in $\mathrm{T}_{2}$ treated bitter gourd, and $\mathrm{T}_{4}$ treated pointed gourd and brinjal as recorded accordingly for shelf life (7.33, 6.63 and 7.30 days), content of vitamin C (39.56, 48.83 and $1.4 \mathrm{mg} / 100 \mathrm{~g})$, microbial infection $(14.64 \%, 0 \%$ and $3.53 \%)$, rate of $\mathrm{pH}$ reduction $(22.59 \%, 10.59 \%$ and $15.45 \%)$, loss of fresh weight $(1.39,1.82$ and 1.65-fold lower than $\mathrm{T}_{1}$ ) and color and firmness scores (1.22 and 1.36; 1.19 and $1.23 ; 1.8$ and 1.39-fold higher than $\mathrm{T}_{1}$ ). From the current study it could be concluded that, the combination of aloe vera and thankuni extract would be considered as a suitable treatment for maintaining postharvest properties in bitter gourd. For pointed gourd and brinjal, the combination of aloe vera, thankuni, onion, garlic and ginger extract would be a suitable extract in this regard.

To cite this article: Pervin, R, Khan, S.A.K.U., Sultana, S., Tabassum, M. and Jui, J.A. 2019. Effect of Plant Extracts on the Postharvest Performances of Vegetables. South Asian J. Agric., 7(1\&2): 38-43.

\section{INTRODUCTION}

Bitter gourd (Momordica charantia) is a tropical or subtropical vine of the family Cucurbitaceae (BSBI, 2007) and pointed gourd (Trichosanthes dioica) is a vine plant from the same family while brinjal (Solanum melongena) is a species of the family Solanaceae (Wiersema, 2015). These vegetables play a vital role in everyday diet being rich in different nutrients including vitamins, minerals, carbohydrate, protein etc. (Bagchi, 2005 and Gopalan et al., 1989). Besides, they have significant medicinal value and also serves as antioxidant (Wang et al., 2014; Grover et al., 2004; Beloin et al., 2005 and Ananya and Sarmistha, 2010). Having these importance the considered vegetables are cultivated worldwide while in Bangladesh during 2015 the total production of bitter gourd was 52332 metric tons from 24133 acres, pointed gourd was 84096 metric ton from 24716 acres and brinjal was 310354 metric tons from 76370 acres of land (BBS, 2015). However, due to improper postharvest handling about $27 \%$ of bitter gourd, $21 \%$ of brinjal and $19-25 \%$ of pointed gourd are damaged every year (Chanda, 2009; Sreekanta, 2015 and Singh and Chandha, 1990) and thereby Bangladeshi farmers face a great loss. A wide variety of postharvest storage systems for vegetables is practiced in Bangladesh including - cold storage, pickling, evaporation, salting, sun drying, freezing, plastic packaging system, combination of blanching and wrapping etc. (Pradip et al., 2014; Sreekanta, 2015). However the process of cold storage is costly for farmers (Pradip et al., 2014) and along with this other processes are also costly and most of them have little or more negative impact on health.
A low-cost postharvest treatment like use of plant extracts do not have any negative impact on health is being used widely in different countries which includes different types of plant extracts (Barakat et al., 2012). But rare use of plant extracts in postharvest treatment is noticed and very little research has been done on it in Bangladesh. In this instance, the study was conducted to evaluate the effectiveness of combined plant extracts in maintaining physico-chemical properties and extending shelf life of these summer vegetables in ambient conditions during postharvest period.

\section{METHODOLOGY}

Plant materials: About $5 \mathrm{Kg}$ of bitter gourd (locally named as 'vhui korola' or 'ucche'), $10 \mathrm{Kg}$ of brinjal (locally named as 'pajia') and pointed gourd (locally named 'bombai') were collected from the farmers' field at Botiaghata and Dumuria, Khulna, Bangladesh. The vegetable samples were collected in the early morning and they were free from any diseases and abnormalities. The vegetable samples were similar in size accordingly.

Preparation of plant extracts: Required amount (about $1 \mathrm{~kg}$ ) of plant materials (aloevera, garlic, onion, ginger and thankuni) were collected and blended maintaining proper sterilization practices and then filtered with the help of Whatman Filter Paper (No.2). The filtrated extracts were taken in an aluminum foil sealed beaker and stored in the refrigerator at $5^{\circ} \mathrm{C}$ until further use (Mia, 2003). For preparing combination of the extracts, equal amount of each single extract was taken and the mixture was made $40 \mathrm{ml}$.The final volume of the combinations were made 
$200 \mathrm{ml}$ with the addition of distilled water (Mia, 2003). The combined extracts were taken to different sterilized plastic bottles with the help of funnel and was prepared for spraying purpose.

Experimental design: The experiment was laid out in a completely randomized design (CRD) with three replications of the treatments having 20 fruits of bitter gourd, brinjal and pointed gourd in each replication. Four treatments were applied on the vegetables under study including control $\left(\mathrm{T}_{1}\right)$, combination of aloe vera and thankuni extract $\left(\mathrm{T}_{2}\right)$, combination of garlic, onion and ginger extract $\left(\mathrm{T}_{3}\right)$ and combination of aloe vera, thankuni, garlic, onion and ginger extract $\left(\mathrm{T}_{4}\right)$.

Application of treatments to vegetables: The vegetable samples were placed on a sterilized surface in different groups. The untreated group was left as control. The others were treated with specific treatment through spraying.

Observations recorded: Treated vegetable samples were observed in every alternate day for physical parameters while chemical parameters were observed at 3 days interval. Data on the following parameters were recorded in the current study.

Change in color and firmness: The changes in color and firmness of vegetables were determined by visual observation on a 1 to 5 scale. For color, the scores were allotted as $1=$ yellow, 2 = yellow green, $3=$ pale green, $4=$ green and $5=$ dark green for bitter gourd and pointed gourd. On the other hand, scores for brinjal were as $1=$ black rotten, $2=$ yellow brown, 3 = yellowish, $4=$ pale and $5=$ standard color. Besides for firmness, scores were allotted as $1=$ rotten, $2=$ very soft, 3 $=$ soft, $4=$ moderate hard and $5=$ very hard for all vegetables.

Weight loss: Weight loss was estimated by using a laboratory grade digital weight measuring balance (AND EK600H) in every alternate day and was expressed as percentage of original weight. The percentage of weight loss was calculated by using

following equation.
Percentage of weight loss $(\% \mathrm{WL})=\frac{\mathrm{IW}-\mathrm{FW}}{\mathrm{IW}} \mathrm{X} 100$

IW = initial weight of vegetables (g)

$\mathrm{FW}=$ final weight of vegetables $(\mathrm{g})$

Determination of $\mathbf{p H}$ : In the current study, the $\mathrm{pH}$ of the vegetable extract was measured by using microprocessor desktop pH meter (HANNA-pH 211). The vegetable extract of $30 \mathrm{ml}$ was taken into a beaker and the probe of $\mathrm{pH}$ meter was kept into the extract for measuring its $\mathrm{pH}$. The digital meter displayed the $\mathrm{pH}$ reading directly (Hilderbrant, 2016).

Determination of Total Soluble Solid (\% Brix) content: Total soluble solid content of vegetables was estimated by using Abbe's refractometer (REF10/111). A drop of vegetable juice squeezed from the respected vegetable was dropped on the prism of refractometer. Percent of TSS was obtained as the direct reading from the instruction (Ranganna, 1979).

Determination of vitamin C content: Vitamin C content in the sample was determined by the following formula suggested by Majumdar and Majumdar (2003)

Vitamin C (mg per $100 \mathrm{gm})=\frac{\mathrm{ex} \mathrm{d} \mathrm{x} \mathrm{b}}{\mathrm{cxa}} \times 100$

Where, $\mathrm{a}=$ weight of sample, $\mathrm{b}=$ volume made with metaphosphoric acid, $\mathrm{c}=$ volume of aliquot taken for estimation, $d=$ dye factor, $e=$ average burette reading for sample and the dye factor

(d) $=\frac{0.5}{\text { Average burette reading for standardization of dye solution }}$

Microbial Test: Slides were prepared by taking sample from infected portion of vegetables and the microbial infection was examined through microscope.

Shelf life: Shelf life for the vegetables treated with different treatments was calculated as the number of day until the score for texture and colour retains more than or equal to 3 . In respect of weight loss, the number of marketable days was counted until the weight loss percentage cross the limit of $25 \%$.

Statistical analysis: The collected data on various parameters were statistically analyzed using STAR (Statistical Tool for Agricultural Research), Version 2.0.1 (IRRI, 2013) statistical package. The means for all the treatments were calculated and analyses of variances (ANOVA) for all the parameters were performed by F-test. The significance of differences between the pairs of means was compared by Least Significant Difference (LSD) test at the $1 \%$ and $5 \%$ levels of probability (Gomez and Gomez, 1984).

\section{RESULTS AND DISCUSSION}

Chemical characteristics: After 8 days of treatment, highest amount of vitamin $\mathrm{C}$ content was recorded in the bitter gourd treated with $\mathrm{T}_{2}(39.56 \mathrm{mg} / 100 \mathrm{~g})$ while it was in $\mathrm{T}_{4}$ treated pointed gourd $(48.83 \mathrm{mg} / 100 \mathrm{~g})$ and brinjal $(1.83 \mathrm{mg} / 100 \mathrm{~g})$ (Fig. 1A). Findings from other researches also support that the use of plant extracts enhance the retention of vitamin $\mathrm{C}$ in vegetables. It was reported that Kagzi limes coated with coconut oil (Bisen et al., 2011), mangoes treated with $20 \%$ neem leaf extract (Nisha and Jain, 2014) and Khasi mandarin fruit treated with the combination of Ocimum sanctum and $A$. barbadebsis extract (Nath et al., 2013) showed maximum retention of vitamin $\mathrm{C}$ after storage. On the other hand, lowest increase in TSS content was noticed in $\mathrm{T}_{3}$ treated bitter gourd $(0.23 \%)$, brinjal $(0.25 \%)$ and untreated pointed gourd $(1.15 \%)$ (Fig. 1B). Barakat et al. (2012), Shindhem et al. (2009) and Flavia et al. (2016) also stated that fruits under biological control as mango treated with neem oil and pera orange coated with propolis extracts exhibited slower increase in TSS content. These findings support the findings on TSS content change in current study.

Besides, $\mathrm{pH}$ reduction rate was the lowest in $\mathrm{T}_{2}$ treated $(0.82$ part lower than $\mathrm{T}_{1}$ ) bitter gourd, and $\mathrm{T}_{4}$ treated pointed gourd and brinjal (0.95-part and 0.70-part lower than $\mathrm{T}_{1}$ respectively) (Fig. 1C). According to Nadimi et al. (2013) and Nisha and Jain (2014), herbal plant extract coating on Valencia orange and $20 \%$ of different plant extracts on mango allowed minimum change in $\mathrm{pH}$ content. These finding are also supportive to the current study. 

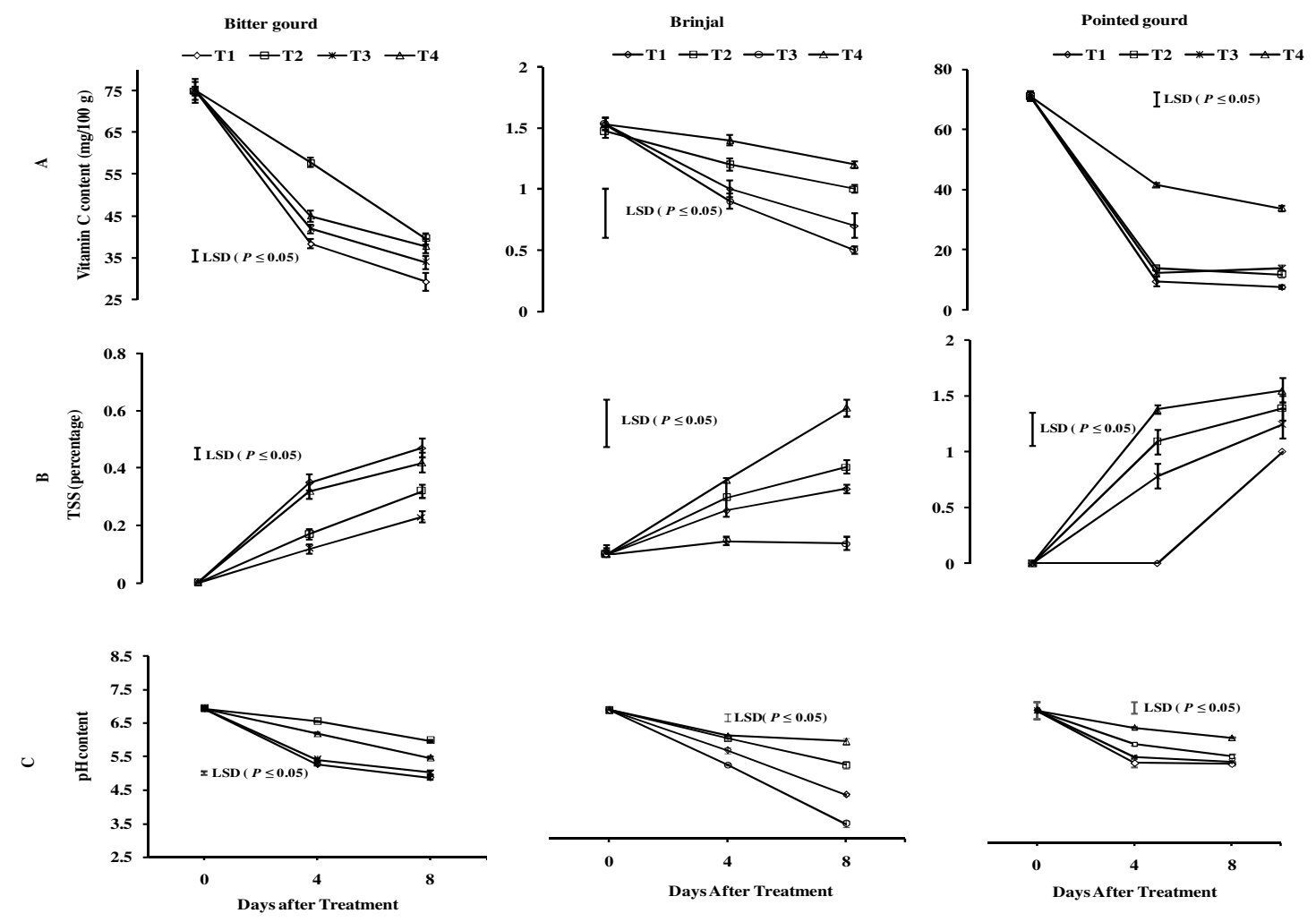

Fig. 1. Changes in chemical parameters in different vegetables due to the effect of treatments with plant extracts $\left(T_{1}, T_{2}, T_{3}\right.$ and $\left.T_{4}\right)$
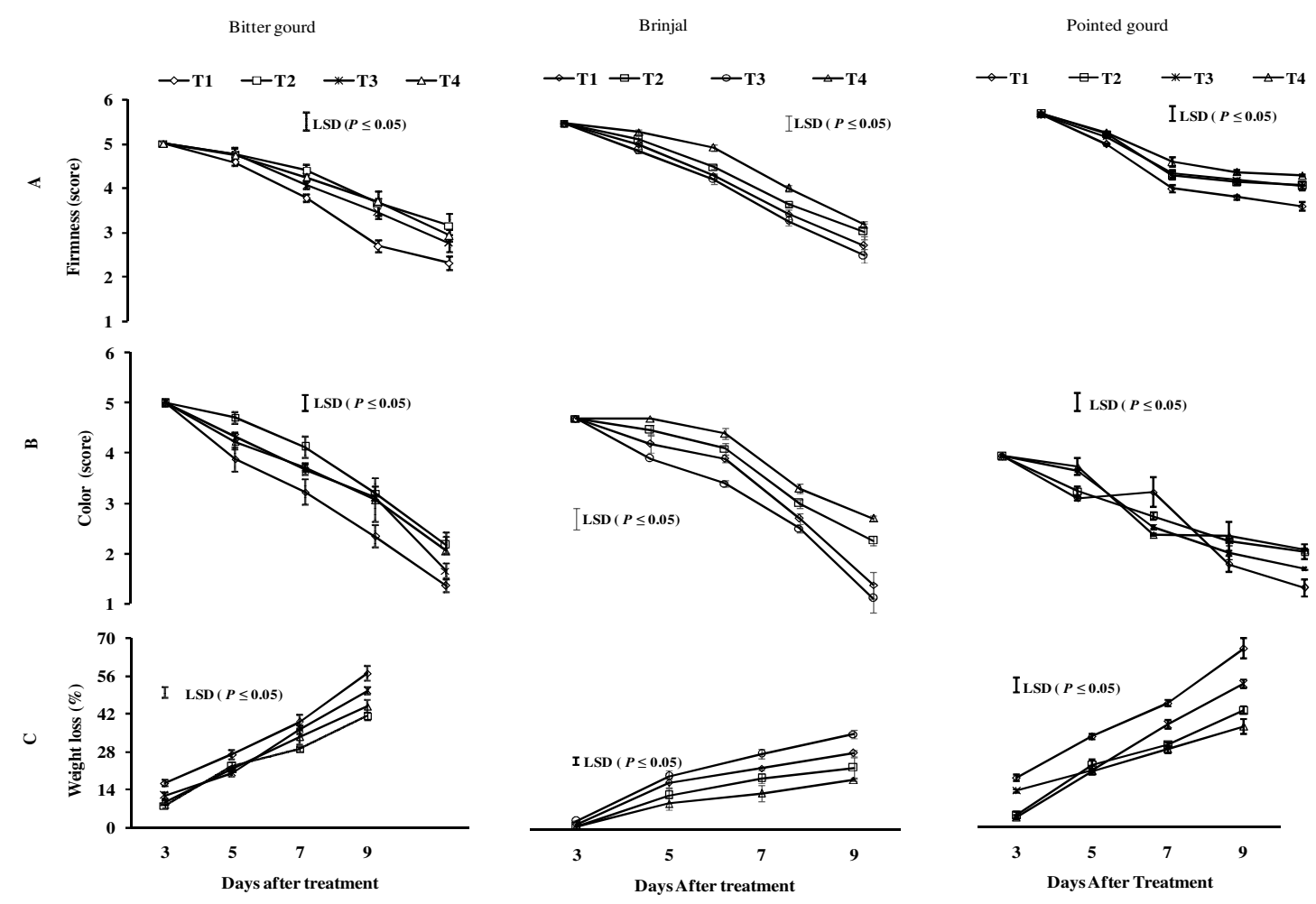

Fig. 2. Changes in physical parameters in different vegetables due to the effect of treatments with plant extracts $\left(T_{1}, T_{2}, T_{3}\right.$ and $\left.T_{4}\right)$ 
Physical characteristics: On 9 DAT (Days After Treatment) for color and firmness, lowest degradation was observed in $\mathrm{T}_{2}$ treated bitter gourd (0.63- and 0.73-part lower than $\left.T_{1}\right)$, and for pointed gourd and brinjal it was noticed in $\mathrm{T}_{4}$ treatment $(0.79$ and 0.60-part; 0.55- and 0.72-part lower than $\mathrm{T}_{1}$ respectively) (Fig. 2 A and Fig. 2B). Findings of Misir et al. (2012) and Alvarez et al. (2015) provided supportive results on color change to the current study where they reported that aloe vera gel coating over fruit's skin and essential oil (tea tree oil) coating over vegetable cuts minimized the color change. Bruini et al. (2012) and Abd-Allah et al. (2012) reported that orange and persimmon fruits treated with garlic extract exhibited lower degradation in firmness which also supports the findings from the current study.

On the other hand, lowest weight loss was found in $\mathrm{T}_{2}$ treated bitter gourd $(41.21 \%), \mathrm{T}_{4}$ treated pointed gourd $(20.23 \%)$ and brinjal (18.21\%) (Fig. 2C). The findings on weight loss of vegetables in the current study is similar to the findings of Shindhem et al. (2009) and Wijewardane and Guleria (2009) who reported that $10 \%$ neem oil coating on fruits and various oil coating on apple are effective in lowering the postharvest weight loss.

Microbial infection: Microbial infection was lowest in $\mathrm{T}_{2}$ treated bitter gourd $(14.64 \%)$ and $\mathrm{T}_{4}$ treated brinjal $(3.33 \%)$ while for pointed gourd $\mathrm{T}_{2}$ and $\mathrm{T}_{4}$ showed no microbial infection (Fig. 3). It was reported that neem extract has good capacity in controlling plant parasitic nematodes (Brahmachari, 2004) and garlic clove completely arrests mycelial growth and spore germination of Phomopsis vexans (Meah, 2007). Those findings are supportive to the findings of the current study.
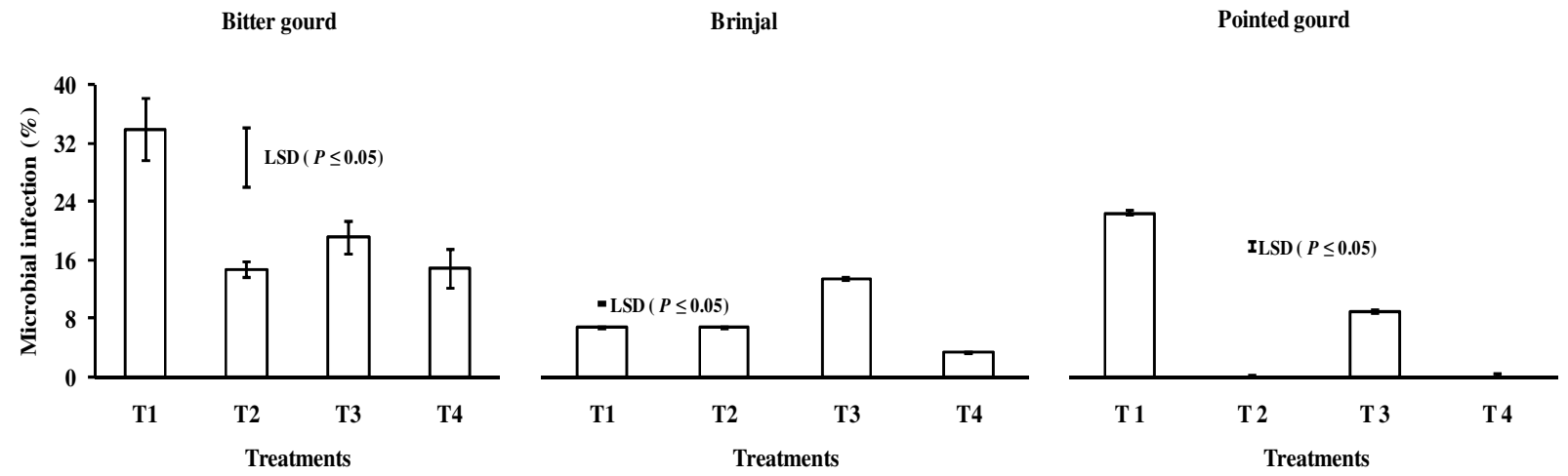

Fig. 3. Microbial infection of different plant extract treated vegetables
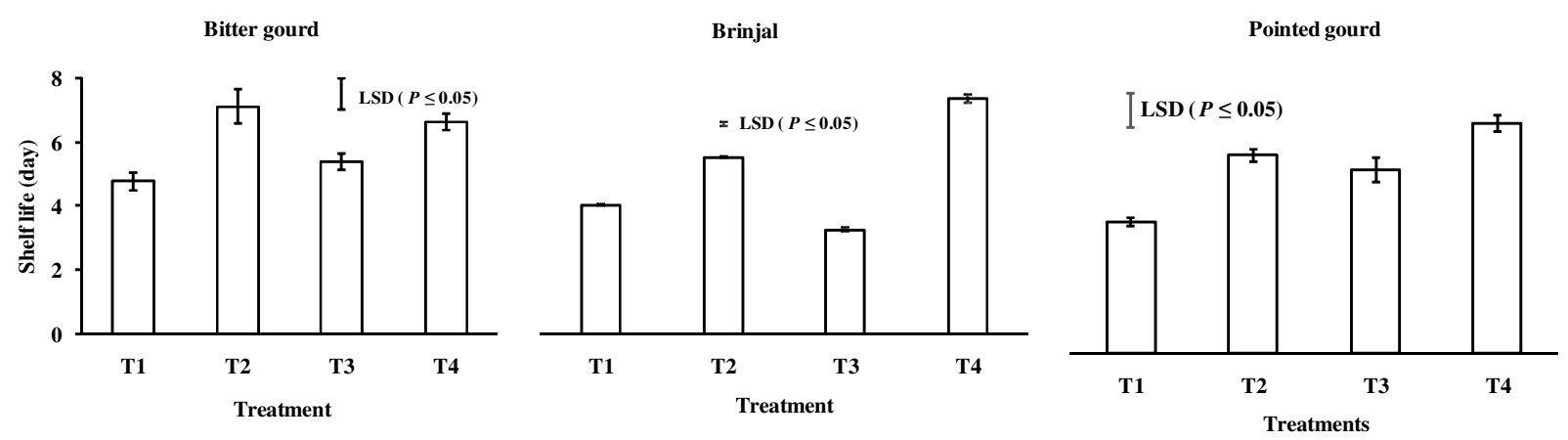

Shelf life: Highest shelf life was recorded in $\mathrm{T}_{2}$ treated bitter gourd (7.33 days), $\mathrm{T}_{4}$ treated pointed gourd (6.63 days) and $\mathrm{T}_{4}$ treated brinjal (7.3 days) (Fig. 4). Walter (2005) and Slogi and Ghorbanpour (2014) reported that, aloe vera extract can preserve fruits and vegetables five time longer period than traditional method and essential oils are effective in extending shelf life of food which support the findings of current study.

\section{SUMMARY AND CONCLUSION}

After 9 days of storage it was found that the quality of vegetables treated with combined plant extract remained better than control. From the findings it could be concluded that combination of aloe vera and thankuni extract $\left(\mathrm{T}_{2}\right)$ or combination of aloe vera, thankuni, onion, garlic and ginger extract $\left(\mathrm{T}_{4}\right)$ can be considered as ideal postharvest treatment for vegetables preservation in ambient conditions having no negative impact on human health and permitting longest market acceptability.

\section{REFERENCES}

Abd-Allah, A.S.E., Abd El-Moneim, A.A.E., Saleh, M.M.S. and El-Naggar, M.A.A. 2012. Effect of jojoba oil emulsion on prolonging storage periods of Costata Persimmon fruits, Asian Journal of Agricultural Science, 4(1):80-88.

Alvarez, M.V., Moreira M.D.R. and Ponce A. 2015. Peroxidase activity and sensory quality of ready to cook mixed vegetables for soup: combined effect of biopreservatives and refrigerated storage, Food Science and Technology, 35(1):86-94.

Pointed gourd

Treatments 
Ananya, P. and Sarmistha, S.R. 2010. Medicinal uses and molecualar identification of two Momordica charantia varieties, Electronic Journal of Biology, 6 (2):43-51.

Bagchi, I. 2005. Food for thought: Green "karela" for Red China, Times of India., pp.4-7 (Retrieved from timesofindia.indiatimes.com on 29 October, 2016).

Barakat M.R., Mohamed M.A.A., Essa, M.A. and Zeinab, A.Z. 2012. Effect of Using Some Biological Post Harvest Treatments on Storability of Washington Navel Orange Fruits Compared with Imazalil Postharvest Chemical Treatments, Journal of Horticultural Science \& Ornamental Plants, 4(1):50-57.

BBS. 2015. Yearbook of Agricultural Statistics of Bangladesh, Ministary of Planning, Government of the People's Republic of Bangladesh, Dhaka.

Beloin, N., Gbeassor, M., Akpagana, K., Hudson, J., De Soussa, K., Koumaglo, K. and Arnason, J.T. 2005. Ethnomedicinal uses of Momordica charantia (Cucurbitaceae) in Togo and relation to its phytochemistry and biological activity, Journal of Ethnopharmacology,96 (1-2): 49-55.

Bisen, A., Panday, S.K. and Patel, N. 2011. Effect of Skin Coating on Prolonging Shelf life of Kagzi lime fruits (Citrus aurantifolia Swingle), Journal of Food Science and Technology-Mysore, 49(6):753-759.

Brahmachari, G. 2004. Neem- an omnipotent plant: a retrospection. Chembiochem, 5(4):408-421.

Brunini, M.A., Archimedes, C.N., Lidiane, A.K., Janaina, C.K. and Vinicius,A.M.J. 2012. Postharvest Treatments on Quality and Shelf Life of "Pera Rio" Orange Fruits, International Conference of Agriculture Engineering, pp. $1-6$.

BSBI (Botanical Society of Britain and Ireland). 2007. (Available from en.wikipedia.org, retrieved on 17 October, 2016).

Chanda, D. 2009. Improper Handling of Bitter gourd, A Quarterly Publication of The Horticulture Export Development Foundation, National Products, 22/1 Topkhana Road, Dhaka-1000, 9:1-2.

Flavia, R.P., Mendes, F.Q., Marilia, C.D.C. and Andre, M.X.D.C. 2016. Propolis Extract Coated In "Pera" Orange Fruits: An Alternative To Cold Storage, African Journal of Agricultural Research, 11(23): 2043-2049.

Gomez, K.A. and Gomez, A.A. 1984. Statistical Procedures for Agricultural Research, Jon Wiley and sons. Inc, New York. pp. 67-215.

Gopalan, C., Ramashashtri, B.V. and Balasubramanian, S.C. 1989. Nutritive values of Indian foods, National Institute of Nutrition Publication, Hyderabad, India.
Grover, J.K. and Yadav, S.P. 2004. Pharmacological actions and potential uses of Momordica charantia: A review, Journal of Ethnopharmacology, 93 (1): 123-132.

Hildebrant, K. 2016. The Guide to $\mathrm{pH}$ Measurement in Food and Drink, Our Daily Brine, (Available from ourdailybrine.com on 3 August, 2016).

IRRI (International Rice Research Institute). 2013. STARStatistical Tool for Agricultural Research, (Available from bbi.irri.org on 12 July, 2016).

Majumdar, B.C. and Majumdar, K. 2003. Methods of Physico Chemical Analysis of Fruits, Daya Publishing House, New Delhi.

Meah, M.B. 2007. Development of an integrated approach for management of Phomopsis blight/fruit rot of eggplant in Bangladesh, Final Research Report (2001-2006), Department of Plant Pathology, Bangladesh Agricultural University, Mymensingh, p. 86.

Mia, B. 2003, Studies on postharvest behavior of papaya, MS thesis, Department of Horticulture, Bangladesh Agricultural University, Mymensingh, PP. 40-96.

Misir, J., Fatema, H.B. and Hoque, M.M. 2012. Aloe vera gel as a Novel Edible Coating for Fresh Fruits, Science and Education Publishing from Scientific Research to Knowledge, 2(3): 2-12.

Nadimi, Z., Jafarpour, M., Mahmoudi, E. and Eghbalsaied, S. 2013. The Effects of "Thiabendazole, Sodium Bicarbonate, Hot Water Dip, Herbal Plant Extract" Treatments and Fruit Size on Valencia Orange Postharvest Quality and Quantity, Journal of Academic and Applied Studies, 3(6): 8-17.

Nath, A., Barman, K., Chandra, S. and Baiswar, P. 2013. Effect of Plant Extracts on Quality of Khasi Mandarin (Citrus reticulata Blanco) Fruits During Ambient Storage, Food and Bioprocess Technology, 6(2): 470-474.

Nisha, G. and Jain, S.K. 2014. Storage Behavior of Mango As Affected By Post-harvest Application of Plant Extracts and Storage Condition, Journal of Food Science and Technology, 51(10): 2499-2507.

Pradip, H., Moniruzzaman, M., Idris A.M. and Md. Mostafizur, R. 2014. Storage System of Potato in Bangladesh, Universal Journal of Agricultural Research, 2(1): 11-17.

Ranganna, S. 1979, Manual of Analysis of Fruit and Vegetable products, Tata McGraw-Hill Pub. Co. Ltd., New Delhi, p. 634.

Shindhem, G.S., Viradia, R.R., Patil, S.A. and Kakade, D.K. 2009. Effect of Posthrvest Treatments of Natural Plant extract and Wrapping material on storage behavior of mango, International Journal of Agricultural Science, 5(2): 420-423. 
Singh, K., and Chadha, K.L. 1990. Vegetable production and policy in India. In: Shanmugasundaram, S, (ed.), Vegetable Research and Development in South Asia. Proceedings of a workshop, held at Islamabad, Pakistan, AVRDC Publication No. 90-331, pp. 89-105.

Solgi, M. and Ghorbanpour, M. 2014. Application of Essential Oils and Their Biological Effects on Extending the ShelfLife and Quality of Horticultural crops, Trakia Journal of Sciences, 2(1): 198-210.

Sreekanta, S. 2015. Packaging Storage and Transportation of Horticultural Produces: Perspective Bangladesh, Logistic (Transportation and storage) Expert Supply Chain Development Component NATP Hortex Foundation, Bangladesh, p.9.

Walter, P. 2005. Aloevera extract may preserve food for longer, Journal of Agriculture and Food Chemistry, 53:7807.

Wang, L., Waltenberge, B., Pferschy, W., Eva, M., Blunder, M., Liu, X., Malainer, C., Blazevic, T., Schwaiger, S., Rollinger, J.M., Heiss, E.H., Schuster, D., Kopp, B., Bauer, R., Stuppner, H., Dirsch, V.M. and Atanasov, A.G. 2014, Natural product agonists of peroxisome proliferator-activated receptor gamma (PPAR $\gamma)$ : a review, Biochemical Pharmacology, 92(1):73-89.

Wiersema, J.H. 2015. GRIN Taxonomy. US National Plant Germplasm System. Checklist dataset https://doi.org/ accessed via GBIF.org on 15 January, 16.

Wijwardane, R.M.N.A. and Guleria, S.P.S. 2009. Combined Effects of Pre-cooling, Application of Natural Extracts and Packaging on the Storage Quality of Apple (Malus domestica) cv. Royal Delicious, Tropical Agricultural Research, 21(1):10-20. 